\title{
ANFIS Based Fault Detection and Identification of Control Valve Failures in Three Tanks Interacting Level Process
}

\author{
S. Nagarajan, K. Kalaivani, P. Navaseelan, T. Kalaiselvi, S. Sobana
}

\begin{abstract}
Fault detection and identification for control valve failures in a three tanks interacting level process (TTILP) and failure accommodation under such failure conditions is presented in this paper. The proposed Fault Detection and Identification is done based on multiple model observer approach and the observers are developed using Adaptive Neuro-Fuzzy Inference System (ANFIS). Four models are developed with a dedicated observer to represent the three control valve failures 'struck at minimum flow position', 'struck at maximum flow position', and 'struck at last maintained position' and the controller failure respectively. Decision functions are developed from the outputs of these models to identify the failures. Fault Confirmation Logic uses two more multiple model observers to avoid false alarms. The three types of control valve failures are considered in this paper. The results show that the TTLIP is able to control perfectly even under any type of control valve failure.
\end{abstract}

Keywords: ANFIS; Dedicated Observer Scheme; Fault Detection and Identification; Control Valve Failures; Three Tanks Interacting Level Proces; Observers.

\section{INTRODUCTION}

The controller gives control inputs to relevant control valves to control the flow to maintain the levels in three tanks interacting level process. When the control valves work without any failures, the control will be perfect. The controller design may result in unsatisfactory performances, in the event of malfunctions in control valves. Some hardware problem may occur in control valves which may result in some locked movement of the actuators and these are treated as control valve failures in this work. The failure may imply a locked position in control valves either at minimum, maximum or the last maintained positions. Any of these failures changes the control action that possibly leads to worse unstable conditions. The failure of control signal given by the state feedback that actuates the control valve may also affect the control valve performance and is

considered as controller failure in this work. To preserve the safety and reliability of the process, the presence of control valve and controller failures should be identified in time and suitable actions should be taken to overcome the unhealthy situation. The decision functions for Fault

Revised Manuscript Received on 14 August, 2019.

S.Nagarajan, Department of Electronics and Instrumentation EngineeringEaswari Engineering College, Chennai, Tamil naduIndia.

K.Kalaivani, Department of Electronics and Instrumentation EngineeringEaswari Engineering College, Chennai, Tamil naduIndia

P.Navaseelan, Department of Electronics and Instrumentation EngineeringEaswari Engineering College, Chennai, Tamil naduIndia

T.Kalaiselvi, Department of Electronics and Instrumentation EngineeringEaswari Engineering College, Chennai, Tamil naduIndia

S.Sobana, Department of Electronics and Instrumentation EngineeringEaswari Engineering College, Chennai, Tamil naduIndia
Detection and Identification logic for Controller and Control valve failures are formed from Multiple model observer. This paper presents the Fault and Identification scheme for Control valve failures.

Most of the Fault Detection and Identification methods to provide analytical redundancy are based on linear quadratic control methodology [1] [2], adaptive control system [3][4] [5], Eigen structure assignment [6] [7] and Multiple model techniques [8] [9] [10]. Sliding mode observer is introduced for a rigid satellite fault diagnosis, subject to faults of external disturbances and thrusters faults [11]. In a fault detection for USV system, a Fault Detection Filter is utilized to construct a residual model and an integral-based event generator is introduced to save communication resources [12]. Fault Detection and Tolerant systems are implemented for internet based three tank system in recent days by applying residual analysis techniques [13]. Since these methods are analytical, purely based on mathematical model of the system, modeling errors may degrade their performances. The Multiple model techniques are suitable only if the numbers of failures are not too big.

Knowledge based systems use process information instead of models of the processes [14] [15]. When observers are designed using intelligent techniques like Fuzzy systems [16] and neural networks [17] [18], mathematical model is not required and the observers can accommodate non-linearities also. An iterative neural network-based observer was used in [19] to achieve robust fault diagnosis for a satellite large angle attitude system. An iterative learning observer-based FDI was reported in to achieve estimation of time-varying thrusters faults [20].

The tuning of membership functions posts a challenge while doing process modeling using fuzzy systems. Neural networks can be used to tune the membership function optimally. If a neural network is trained with process inputoutput relationships as training data, optimal shape of the membership functions can be achieved. The Adaptive neuro-fuzzy system, which is a neural network, fixes the optimal shape and parameters for the membership functions and effective rule base for the fuzzy system for observer modeling.

The author in his previous work [21] [22] implemented ANFIS based Fault Detection and Identification for sensor faults in three tanks interacting level process. Control has been designed and applied through State feedback to control tank levels in TTILP taking level values from level sensors

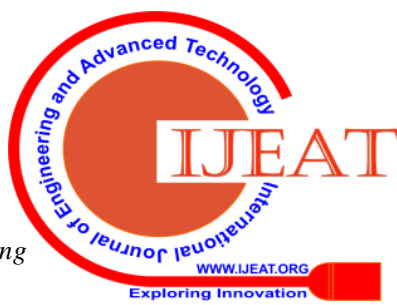




\section{ANFIS BASED FAULT DETECTION AND IDENTIFICATION OF CONTROL VALVE FAILURES IN THREE TANKS INTERACTING LEVEL PROCESS}

as state variables. Three pairs of Adaptive neuro-fuzzy observers are designed with level sensor outputs as inputs. State estimation of the three state variables is performed by these ANFIS observers. One measured value from level sensor and one estimated value from ANFIS observer is available for each tank level. If any level sensor gets failed, the failure is detected by Fault Detection and Identification method. On detection of fault, control law is reconfigured so that the state feedback control takes level information from the estimated value instead of measured value. This method is extended to Fault Detection and Identification of Control Valve failure in this paper with Multiple Model approach developed using ANFIS.

\section{MATHEMATICAL MODEL}

The experimental set-up and schematic diagram of threetanks interacting level process are shown in Fig. 1 and Fig. 2 respectively. The open loop dynamics of the process is described by the following equations [21]:

$$
\begin{aligned}
& \frac{d h_{1}(t)}{d t}=-\frac{\beta_{12} a_{12}}{A_{1}} \sqrt{2 g\left(h_{1}(t)-h_{2}(t)\right)}+\frac{k_{1}}{A_{1}} u_{1} \\
& \frac{d h_{2}(t)}{d t}=\frac{\beta_{12} a_{12}}{A_{2}} \sqrt{2 g\left(h_{1}(t)-h_{2}(t)\right)}-\frac{\beta_{23} a_{23}}{A_{2}} \sqrt{2 g\left(h_{2}(t)-h_{3}(t)\right)} \\
& \frac{d h_{3}(t)}{d t}=\frac{\beta_{23} a_{23}}{A_{3}} \sqrt{2 g\left(h_{2}(t)-h_{3}(t)\right)}-\frac{\beta_{3} a_{3}}{A_{3}} \sqrt{2 g h_{3}(t)}+\frac{k_{2}}{A_{3}} u_{2}
\end{aligned}
$$

where $\mathrm{u}_{1}$ and $\mathrm{u}_{2}$ are the control inputs to the control valves $C V_{1}$ and $C V_{2}$ respectively, $h_{1}, h_{2}$ and $h_{3}$ are the level in tank $1, \operatorname{tank} 2$ and tank 3 respectively. $\mathrm{A}_{1}, \mathrm{~A}_{2}$ and $\mathrm{A}_{3}$ are the cross section area of tank1, tank 2 and tank 3 respectively. a12, a23, a3 are cross section area of pipe lines connecting corresponding tanks. $\beta$ valuesare valve ratios and $g$ is the gravity in $\mathrm{cm} / \mathrm{s}^{2}$.

Linear state space model can be represented by the following state equations after linearising about the operating point:

$$
\begin{aligned}
& \frac{d X}{d t}=A X+B U \\
& Y=C X
\end{aligned}
$$

with state vector $\mathrm{X}$ and control input $\mathrm{U}$ as

$$
\begin{aligned}
X^{T} & =\left[\begin{array}{lll}
h_{1} & h_{2} & h_{3}
\end{array}\right] \\
U^{T} & =\left[\begin{array}{lll}
u_{1} & u_{2} & 1
\end{array}\right]
\end{aligned}
$$

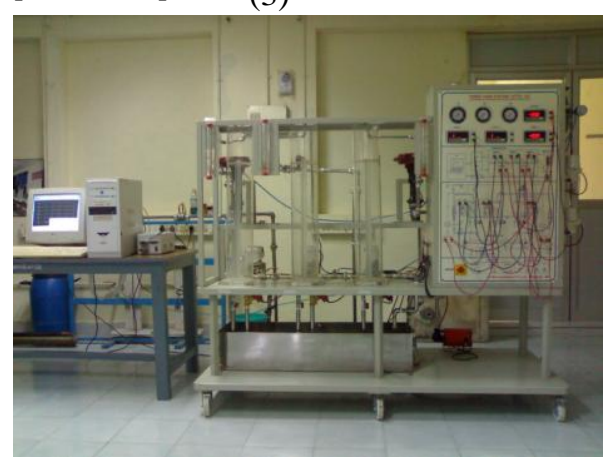

Fig 1: Experimental set-up of TTILP

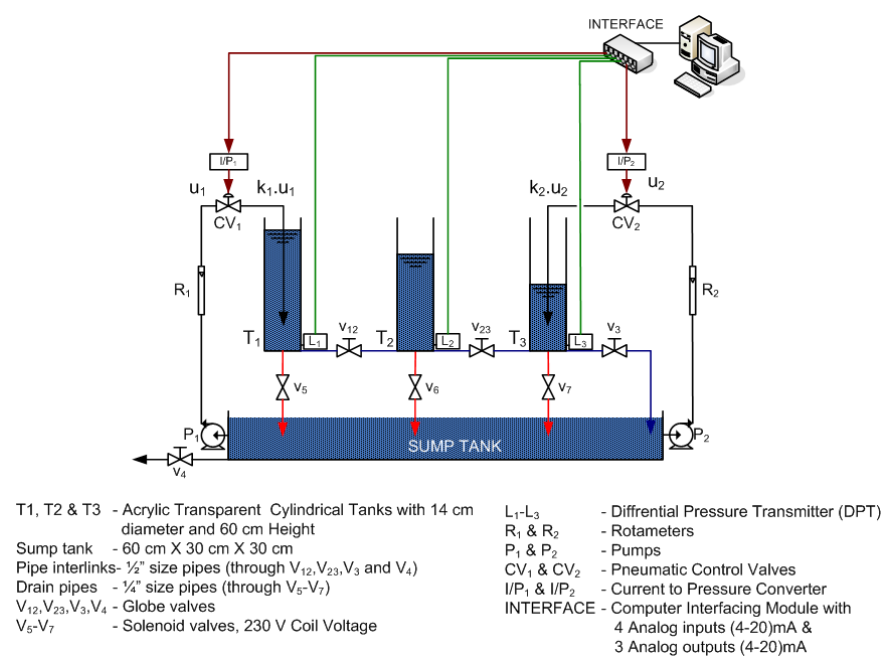

Fig 2: Schematic diagram of TTILP

With the levels $\mathrm{H}_{1}, \mathrm{H}_{2}$ and $\mathrm{H}_{3}$ in tank 1, tank 2 and tank 3 respectively at the operating point, the matrices $\mathrm{A}, \mathrm{B}$ and $\mathrm{C}$ in (2) are given by

$$
\begin{aligned}
& A=\left[\begin{array}{ccc}
-\frac{1}{T_{12}} & \frac{1}{T_{12}} & 0 \\
\frac{1}{T_{12}^{\prime}} & -\left(\frac{1}{T_{12}^{\prime}}+\frac{1}{T_{23}}\right) & \frac{1}{T_{23}} \\
0 & \frac{1}{T_{23}^{\prime}} & -\left(\frac{1}{T_{23}^{\prime}}+\frac{1}{T_{3}}\right)
\end{array}\right] \\
& B=\left[\begin{array}{ccc}
\frac{k_{1}}{A_{1}} & 0 & -\frac{1}{T_{12}} \sqrt[3]{H_{1}-H_{2}} \\
0 & 0 & \frac{1}{T_{12}^{\prime}} \sqrt[3]{H_{1}-H_{2}}-\frac{1}{T_{23}} \sqrt[3]{H_{2}-H_{3}} \\
0 & \frac{k_{2}}{A_{3}} & \frac{1}{T_{23}^{\prime}} \sqrt[3]{H_{2}-H_{3}}-\frac{1}{T_{3}} \sqrt[3]{H_{3}}
\end{array}\right]
\end{aligned}
$$

where

$$
\begin{aligned}
& T_{12}=\frac{A_{1}}{\beta_{12} a_{12}} \sqrt{\frac{2\left(H_{1}-H_{2}\right)}{g}}, T_{12}^{\prime}=\frac{A_{2}}{\beta_{12} a_{12}} \sqrt{\frac{2\left(H_{1}-H_{2}\right)}{g}}, \\
& T_{23}=\frac{A_{2}}{\beta_{23} a_{23}} \sqrt{\frac{2\left(H_{2}-H_{3}\right)}{g}}, T_{23}^{\prime}=\frac{A_{3}}{\beta_{23} a_{23}} \sqrt{\frac{2\left(H_{2}-H_{3}\right)}{g}} \\
& T_{3}=\frac{A_{3}}{\beta_{3} a_{3}} \sqrt{\frac{2 H_{3}}{g}},
\end{aligned}
$$

Table I gives the process parameters and table lists the process operating point.

Table 1: Process Parameters

\begin{tabular}{|c|c|l|l|l|c|}
\hline $\begin{array}{c}A_{1}, A_{2}, \\
A_{3}\left(\mathrm{~cm}^{2}\right)\end{array}$ & $\begin{array}{c}a_{12}, a_{23}, \\
a_{3}\left(\mathrm{~cm}^{2}\right)\end{array}$ & $\beta_{12}$ & $\beta_{23}$ & $\beta_{3}$ & $\begin{array}{l}k_{1}, k_{2}\left(\mathrm{~cm}^{3}\right. \\
1 \% . \mathrm{s})\end{array}$ \\
\hline 615.7522 & 1.2272 & 0.9 & 0.8 & 0.3 & 8 \\
\hline
\end{tabular}
Table 2 :Process Operating Point

\begin{tabular}{|c|c|c|c|c|}
\hline $\begin{array}{c}H_{l}(\mathrm{c} \\
\mathrm{m})\end{array}$ & $\begin{array}{c}H_{2} \\
(\mathrm{~cm})\end{array}$ & $\begin{array}{c}H_{3} \\
(\mathrm{~cm})\end{array}$ & $u_{l}(\%)$ & $\begin{array}{c}\mathrm{u}_{2} \\
(\%)\end{array}$ \\
\hline 55.66 & 50.7 & 44.45 & 80 & 10 \\
\hline
\end{tabular}

\section{STATE FEEDBACK CONTROL}

The state feedback control system (SFCS) is developed with the objective to maintain the level $h_{3}$ in tank 3 at the desired value. SFCS uses the level values from three sensors directly whilethey arenormal and from estimated values while they fail. 
The desired closed loop poles can be achieved by pole placement technique by means of state feedback [22]. The state feedback control scheme is shown in Fig.3. The integral control with gain $\mathrm{K}_{\mathrm{I}}$ is introduced to provide zero steady state error. The control is done by controlling $u_{l}$ only with a fixed $u_{2}$ in this work. The values of $\mathrm{K}_{\mathrm{I}}, \mathrm{K}_{1}, \mathrm{~K}_{2}$ and $\mathrm{K}_{3}$ are $0.2,3.7707,3.5659$ and 3.1659 respectively. The state feedback control design is well explained in author's previous work [21] [23].

\section{ADAPTIVE NEURO-FUZZY INFERENCE SYSTEM (ANFIS).}

The proposed FDI system uses Adaptive Neuro-Fuzzy Inference System (ANFIS) which is functionally equivalent to Sugeno fuzzy model. ANFIS is the combination of an Artificial Neural Network (ANN) and a Fuzzy Inference System (FIS). In ANFIS Dedicated Observers, observers are developed as FIS. The parameters of this FIS are optimally determined by ANN. The architecture of ANFIS is shown in Fig.4 [24]. ANFIS has a five layered architecture. The first hidden layer is for fuzzification of the input variables and $\mathrm{T}$ norm operators are deployed in the second hidden layer to compute the rule antecedent part. The third hidden layer normalizes the rule strengths followed by the fourth hidden layer where the consequent parameters of the rule are determined. Output layer computes the overall input as the summation of all incoming signals.

ANFIS uses back-propagation learning to determine premise parameters to learn the parameters related to membership functions and least mean squares estimation to determine the consequent parameters. The learning of neural network is done through back propagation in which the input patterns are propagated as phase 1 to estimate the optimal consequent parameters and the premise parameters are modified as second phase with fixed consequent parameters.

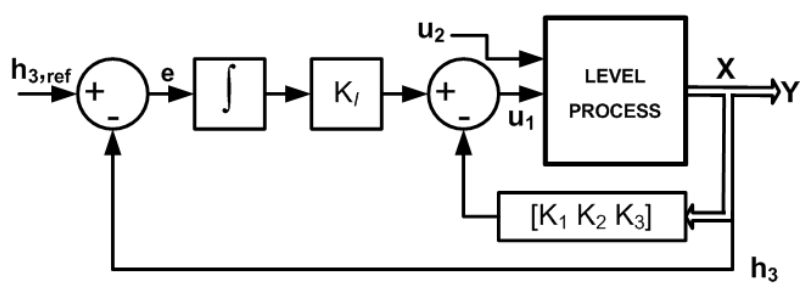

Fig 3: State feedback with Integral control

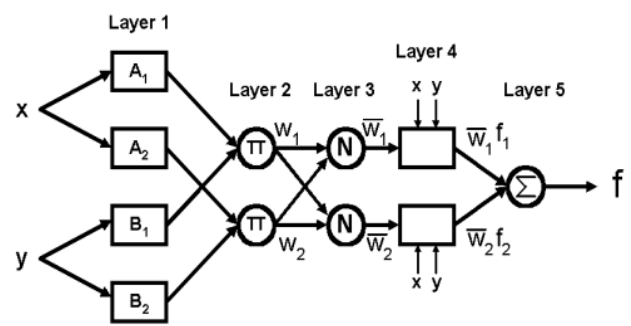

Fig 4 :Architecture of an Adaptive Neuro-Fuzzy Inference System

Every node $i$ in layer 1 is an adaptive node with a node function whose output is equal to the membership grade of the particular input given by

$$
O_{1, i}=\mu_{A_{i}}(x) \text {, for } i=1,2 \text { or }
$$

$$
O_{1, i}=\mu_{B_{i-2}}(y) \text {, for } i=3,4(10)
$$

wherex (or $y$ ) is the input to node $i$ and $A_{i}$ (or $B_{i-2}$ ) is a linguistic label associated with this node. Here the membership function used is a Gaussian function given by

$$
\mu_{A}(x)=\exp \left(\frac{-0.5\left(x-c_{i}\right)^{2}}{\sigma_{i}{ }^{2}}\right)
$$

where $c_{i}$ and $\sigma_{i}$ is the mean and variance of the Gaussian membership function respectively.

Every node in layer 2 is a fixed node and represents the firing strength of a rule. The output of each node is a product of all the incoming signals as given by

$$
O_{2, i}=w_{i}=\mu_{A_{i}}(x) \cdot \mu_{B_{i}}(y), \quad i=1,2
$$

Every node in layer 3 is a fixed node and calculates the ratio of firing strength of a rule to the sum of all rules firing strengths. The outputs of this layer are normalized firing strengths given by

$$
O_{3, i}=\overline{w_{i}}=\frac{w_{i}}{w_{1}+w_{2}},
$$

Each node layer 4 is an adaptive node with a node function given by

$$
O_{4, i}=\overline{w_{i}} \cdot f_{i}=\overline{w_{i}}\left(p_{i} x+q_{i} y+r_{i}\right),
$$

where $\left\{p_{i}, q_{i}, r_{i}\right\}$ is the parameter set of this node.

The single fixed node in layer 5 computes the overall output as the summation of all incoming signals as given by

$$
O_{5, i}=\sum \overline{w_{i}} \cdot f_{i}=\frac{\sum_{i} w_{i} \cdot f_{i}}{\sum_{i} w_{i}}
$$

\section{ADAPTIVE NEURO-FUZZY DEDICATED OBSERVERS FOR STATE ESTIMATION}

An adaptive network with above structure, which is functionally equivalent to Sugeno fuzzy model, is constructed as an observer with three inputs to give the estimated state value as its output. Six adaptive neuro-fuzzy observers are designed and observers for state $x_{3}$ estimation is shown in Fig.5.

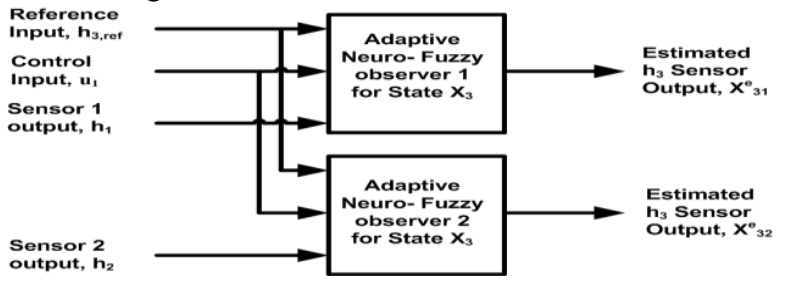

Fig 5: Adaptive neuro-fuzzy Dedicated observer for state $x_{3}$ estimation

The experimental open loop data with outputs for known inputs is used to train the ANN. The architecture of one such Adaptive Neuro-Fuzzy Inference System as state $x_{3}$ observer is shown in Fig. 6.

The trained ANN fixes the shape, parameters for the membership functions and effective rule base for FIS. The input membership functions are Gaussian and output membership functions are linear. The optimal numbers of

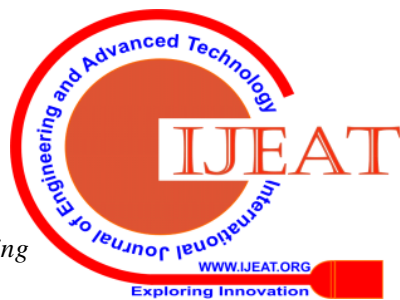


membership functions of these observers are tabulated in Table III.

Table III Optimal Numbers of Membership Function

\begin{tabular}{|c|c|c|}
\hline $\begin{array}{l}\text { Observer } \\
\text { output }\end{array}$ & $\begin{array}{l}\text { No. of } \\
\text { membership } \\
\text { functions for each } \\
\text { input }\end{array}$ & $\begin{array}{l}\text { No. of } \\
\text { membership } \\
\text { functions for } \\
\text { output }\end{array}$ \\
\hline$X_{12}$ & 20 & 20 \\
\hline$X_{13}$ & 21 & 21 \\
\hline$X_{21}$ & 20 & 20 \\
\hline$X_{23}$ & 8 & 8 \\
\hline$X_{31}$ & 12 & 12 \\
\hline$X_{32}$ & 9 & 9 \\
\hline
\end{tabular}

The mean, $\mathrm{c}$ and variance, $\sigma$ of membership functions (mf) for state $x_{32}$ and $x_{31}$ observers are shown in Table IV and Table $\mathrm{V}$ respectively. Corresponding membership functions are shown in Fig. 7 and Fig. 8.

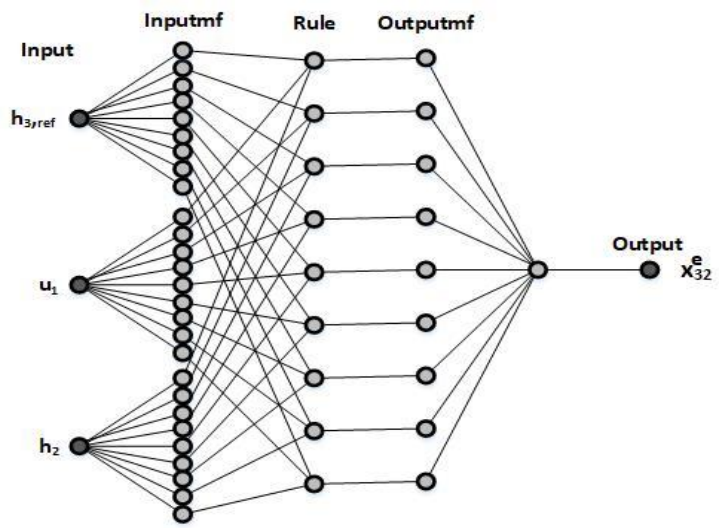

Fig 6: Architecture of ANFIS observer
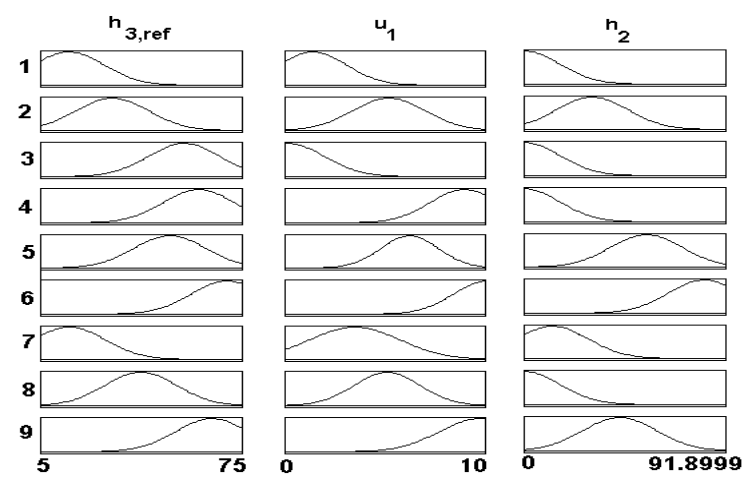

Fig 7: Membership functions of State $x_{32}$ observer
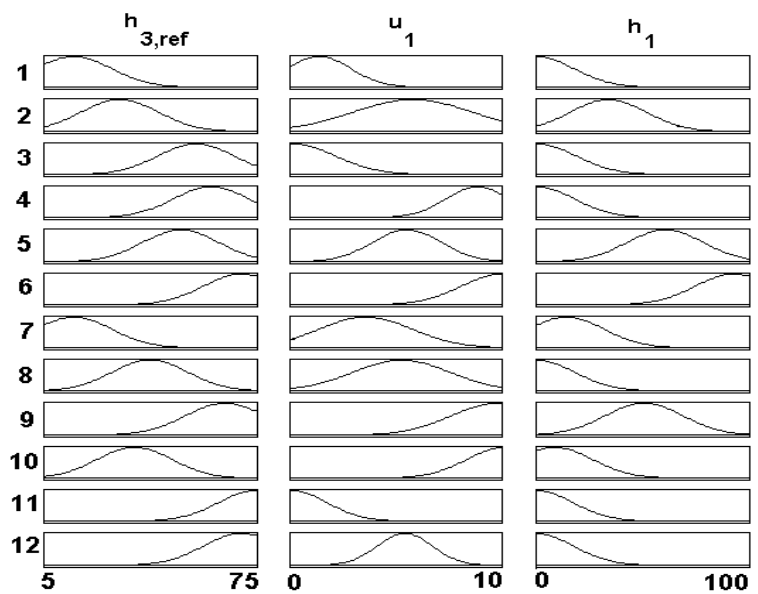

Fig 8:Membership functions of State $x_{31}$ observer
Table IV Optimal Parameters of Membership Functions of $x_{32}$ Observer

\begin{tabular}{|l|l|l|l|l|l|l|}
\hline \multirow{2}{*}{$\mathrm{mf}$} & Input 1 & \multicolumn{2}{|l|}{ Input 2 } & Input 3 \\
\cline { 2 - 7 } & $\mathrm{c}$ & $\sigma$ & $\mathrm{c}$ & $\sigma$ & $\mathrm{c}$ & $\sigma$ \\
\hline 1 & 14.98 & 12.26 & 1.41 & 1.676 & 0.01353 & 16.25 \\
\hline 2 & 30.05 & 30.05 & 5.197 & 1.813 & 31.24 & 16.25 \\
\hline 3 & 55 & 55 & 0.145 & 1.82 & 0.244 & 16.2 \\
\hline 4 & 60.09 & 60.09 & 8.962 & 1.703 & -0.06657 & 16.23 \\
\hline 5 & 50.1 & 50.1 & 6.24 & 1.43 & 56.02 & 16.3 \\
\hline 6 & 70.01 & 70.01 & 10.1 & 1.68 & 82.38 & 16.35 \\
\hline 7 & 15.07 & 15.07 & 3.492 & 2.242 & 13.18 & 16.23 \\
\hline 8 & 39.98 & 39.98 & 5.11 & 1.639 & 0.07836 & 16.35 \\
\hline 9 & 64.77 & 64.77 & 9.716 & 2.004 & 43.83 & 16.72 \\
\hline
\end{tabular}

Table V: Optimal Parameters of Membership Functions of $x_{31}$ Observer

\begin{tabular}{|l|l|l|l|l|l|l|}
\hline \multirow{2}{*}{$\mathrm{mf}$} & \multicolumn{7}{|l|}{ Input 1 } & Input 2 & Input 3 \\
\cline { 2 - 7 } & $\mathrm{c}$ & $\sigma$ & $\mathrm{c}$ & $\sigma$ & $\mathrm{c}$ & $\sigma$ \\
\hline 1 & 15.01 & 12.38 & 1.369 & 1.505 & 0.03488 & 17.69 \\
\hline 2 & 30.07 & 12.57 & 5.803 & 2.793 & 34.03 & 17.6 \\
\hline 3 & 55.06 & 12.35 & 0.1382 & 1.997 & 0.1141 & 18.63 \\
\hline 4 & 60.02 & 12.28 & 8.852 & 1.475 & 0.3819 & 17.73 \\
\hline 5 & 50.11 & 12.34 & 5.54 & 1.61 & 60.79 & 17.66 \\
\hline 6 & 70 & 12.42 & 10.03 & 1.914 & 92.77 & 17.81 \\
\hline 7 & 15.2 & 12.4 & 3.576 & 2.187 & 14.4 & 17.65 \\
\hline 8 & 40.01 & 12.35 & 5.263 & 2.276 & 0.2737 & 17.82 \\
\hline 9 & 64.8 & 12.9 & 9.764 & 2.219 & 50.88 & 18.01 \\
\hline 10 & 34.9 & 12.2 & 10.12 & 1.765 & 8.744 & 17.88 \\
\hline 11 & 75.05 & 12.39 & 0.05599 & 1.683 & - & 17.38 \\
& & & & & 0.04165 & \\
\hline 12 & 69.97 & 12.38 & 5.427 & 1.284 & 0.02131 & 17.54 \\
\hline
\end{tabular}

Since these observers are designed based on input-output relationships instead of mathematical model of a process, this FDI overcomes the problem of modeling errors and the difficulties encountered in developing accurate analytical observers using mathematical model. ANFIS based Fault Detection and Identification can detect and identify any control valve failure and reconfigure the control law.

This method uses the Dedicated Observer Scheme (DSO) for residual evaluation. The level sensor output is the input to DOS and the estimated state values of other two level values are the outputs. One DOS for each level value is designed and implemented. Thus one measured value and two estimated values are available for each level measurement all the time.

\section{FDI FOR ACTUATOR AND CONTROLLER FAILURES}

In control valve, the actuators may be struck at one position even if the control valve receives the control signal from the controller. The following types of actuator failures are considered in control valve $\mathrm{CV}_{1}$ actuated by input $\mathrm{u}_{1}$ :

1. Control valve struck at maximum flow positio

2. Control valve struck at minimum flow position

3. Control valve struck at some last maintained position 
Control valve struck at maximum flow position gives maximum flow and so the process may become uncontrollable. Control valve at minimum flow position gives no flow to the tank and the tanks become empty with their levels at $0 \mathrm{~cm}$. Both the conditions are undesirable. These actuator failures should be detected in time so that the process is safe and controllable.

Control valves receive the control signal as pneumatic signal in three tanks interacting level process. Hence the failure of control signal is possible due to the failure of air supply. In this work, the total failure of control input $\mathrm{u}_{1}$ is considered as controller failure in this work which in turn makes the control valve $\mathrm{CV}_{1}$ to reside at minimum flow position. The control input $\mathrm{u}_{2}$ is assumed to be available without any failure in this paper. The control input $u_{1}$ is available for all observers in the case of actuator failure, struck at minimum flow position whereas the control input is not available for observers and control valve $\mathrm{CV}_{1}$ in the case of controller failure.

Fault detection and identification system for control valve failures performs four functions: Fault Detection, Fault Identification, Fault confirmation and Reconfiguration of control law.

\section{Generation of Decision functions for Fault detection}

The states of the process are the outputs of perfect sensors as given by

$$
\begin{aligned}
& \mathrm{x}_{1}=\mathrm{h}_{1}, \\
& \mathrm{x}_{2}=\mathrm{h}_{2} \text { and } \\
& \mathrm{x}_{3}=\mathrm{h}_{3}
\end{aligned}
$$

The dedicated observers with $h_{2}$ and $h_{3}$ sensor outputs as inputs respectively give the estimated states for state $\mathrm{x}_{1}$ as $\mathrm{x}_{12}^{\hat{1}}$ and $\mathrm{x}_{13}$ respectively. The error functions are given by

$$
\left.\begin{array}{l}
\mathrm{f}_{11}=\left|\hat{x_{13}}-\mathrm{x}_{12}\right| \\
\mathrm{f}_{21}=\left|\mathrm{x}_{13}-\mathrm{x}_{1}\right| \\
\mathrm{f}_{31}=\left|\mathrm{x}_{12}-\mathrm{x}_{1}\right|
\end{array}\right\}
$$

The decision functions $\eta_{11}, \eta_{21}$ and $\eta_{31}$ are formed as

$$
\left.\begin{array}{l}
\eta_{11}=\mathrm{f}_{21} \mathrm{f}_{31} \\
\eta_{21}=\mathrm{f}_{11} \mathrm{f}_{31} \\
\eta_{31}=\mathrm{f}_{11} \mathrm{f}_{21}
\end{array}\right\}
$$

Under 'No sensor failure condition', the measured values and the estimated values are same and hence the error functions $f_{11}, f_{21}$ and $f_{31}$ are zero which result in zero values of decision functions $\eta_{11}, \eta_{21}$ and $\eta_{31}$.

Under sensor failure, two error functions involving the value taken from the failed sensor will show larger deviation. The decision function involving these two error functions in its product will show great deviation. The deviation in the decision function fires the Fault alarm for the failed sensor. Since even small deviation in decision functions may fire false Fault alarm, threshold values are fixed for decision functions. The threshold values of decision functions $\eta_{11}, \eta_{21}$ and $\eta_{31}$ are fixed as 40,35 and 25 respectively. Similar set of decision functions $\left[\eta_{12}, \eta_{22}, \eta_{32}\right]$ and $\left[\eta_{31}, \eta_{32}, \eta_{33}\right]$ are generated from the set of values of $x_{2}$ and $\mathrm{x}_{3}$ respectively from dedicated observers.
Actuator fault detection uses the decision functions generated for detection of sensor failures. The trends of sensor decision functions on failures of actuator struck at maximum flow position and at minimum flow position are shown in Fig.9 and Fig.10 respectively.

On studying the trends of decision functions under actuator failures, it is learned that the decision functions generated for identification of $h_{2}$ level sensor failure grow faster on all types of actuator failures. Hence the actuator fault detection uses the decision functions $\eta_{21}, \eta_{22}$ and $\eta_{23}$.
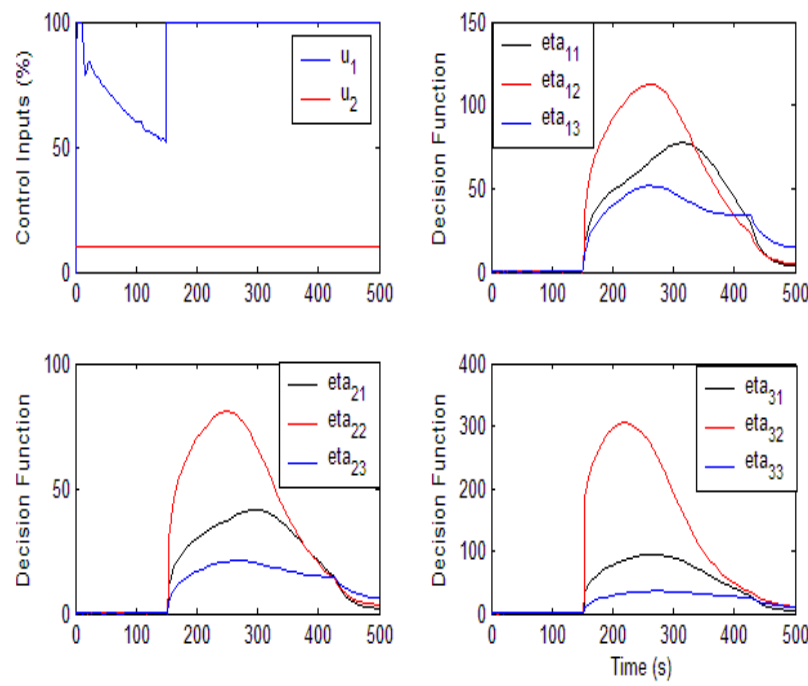

Fig 9 Decision functions on actuator struck at maximum flow position
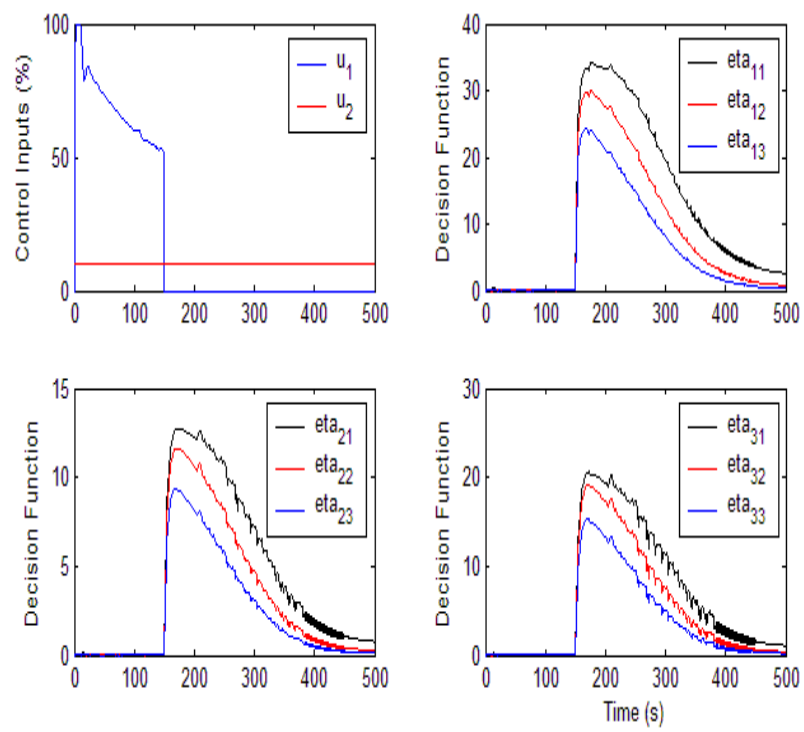

Fig 10 Decision functions on actuator struck at minimum flow position

The decision function for detection of actuator failure is given by

$$
\eta_{\mathrm{A}}=\eta_{21} \cdot \eta_{22} \cdot \eta_{23}
$$



TANKS INTERACTING LEVEL PROCESS

Since this value exceeds 6000 for all actuator faults, the threshold value for $\eta_{A}$ is fixed at 6000. If the decision function $\eta_{\mathrm{A}}$ exceeds this value, an actuator fault flag $\mathrm{F}_{\mathrm{ACT}}$ will be generated.

\section{Actuator Fault Identification}

Actuator fault identification logic identifies the type of actuator fault. New decisions functions are formed for actuator fault identification based on Multiple Model Observer (MMO). The Multiple model observer uses one of the dedicated observers designed for state estimation in sensor fault detection and identification system. Four models are formed from the same observer with different inputs so that each model represents one actuator fault. The multiple model observer arrangement with dedicated observer of state $\mathrm{x}_{3}$ is shown in Fig. 11 .

All the four models of the dedicated observer are given with state $x_{3}$ as one of the inputs. The second input to each observer is control input $\mathrm{u}_{1}$ but with different values. The flow delivered by the control valve $\mathrm{CV}_{1}$ under 'struck at minimum position' is expected to be the same as the flow delivered by the valve when the control input $\mathrm{u}_{1}$ is $0 \%$ and hence this value is given to model 1 which represents 'struck at minimum position'. The flow delivered by the valve under 'struck at maximum position' is the same as the flow delivered by the valve when the control input $u_{1}$ is $100 \%$ and this value is given as input to the model 2 to represent ' struck at maximum position'. If the control valve is struck at last maintained position, the control input corresponding to this position is fixed as input to model 3 to represent 'struck at last maintained position'.

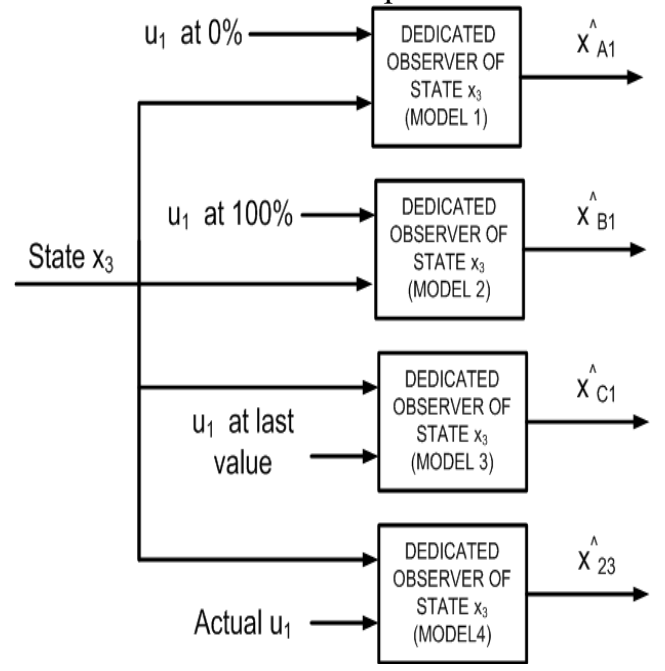

Fig 11: Multiple Model Observers

\section{MULTIPLE MODEL OBSERVERS\& RESULTS}

Model 1 of the dedicated observer is given with minimum value, $0 \%$ and the model 2 is given with maximum value, $100 \%$. Model 3 is given with the actual value of $u_{1}$ but its value will be fixed at last value if actuator fault flag $\mathrm{F}_{\mathrm{ACT}}$ is set. Model 4 is the dedicated observer itself.

The estimates of $\mathrm{x}_{2}$ given by these models are $\mathrm{x}_{\mathrm{A} 1}, \mathrm{x}_{\mathrm{B} 1}, \hat{\mathrm{x}}_{\mathrm{C} 1}$ and $\hat{\mathrm{x}}_{23}$ respectively and the error functions are formed from the estimation errors of these estimates. The error functions are given by

$$
\left.\begin{array}{l}
\mathrm{f}_{\mathrm{A} 1}=\left|\mathrm{x}_{2}-\hat{\mathrm{x}}_{\mathrm{A} 1}\right| \\
\mathrm{f}_{\mathrm{B} 1}=\left|\mathrm{x}_{2}-\hat{\mathrm{x}}_{\mathrm{B} 1_{1}}\right| \\
\mathrm{f}_{\mathrm{C} 1}=\left|\mathrm{x}_{2}-\mathrm{x}_{\mathrm{C} 1}\right| \\
\mathrm{f}_{\mathrm{U} 1}=\left|\hat{\mathrm{x}}_{\mathrm{A} 1}-\mathrm{x}_{23}\right|
\end{array}\right\}
$$

and the actuator fault decision functions are given by

$$
\left.\begin{array}{l}
\eta_{\mathrm{A} 1}=\mathrm{f}_{\mathrm{B} 1} \mathrm{f}_{\mathrm{Cl}} \mathrm{f}_{\mathrm{U} 1} \\
\eta_{\mathrm{B} 1}=\mathrm{f}_{\mathrm{A} 1} \mathrm{f}_{\mathrm{Cl}} \mathrm{f}_{\mathrm{U} 1} \\
\eta_{\mathrm{C} 1}=\mathrm{f}_{\mathrm{A} 1} \mathrm{f}_{\mathrm{B} 1} \mathrm{f}_{\mathrm{U} 1} \\
\eta_{\mathrm{U} 1}=\mathrm{f}_{\mathrm{A} 1} \mathrm{f}_{\mathrm{B} 1} \mathrm{f}_{\mathrm{C} 1}
\end{array}\right\}
$$

The actuator fault identification system will start determining the decision functions only if the actuator fault flag $\mathrm{F}_{\mathrm{ACT}}$ is set. When the actuator is struck at 'minimum struck position', the state $\mathrm{x}_{2}$ and state estimate $\hat{\mathrm{x}}_{\mathrm{A} 1}$ are expected to be equal since they are applied with same control input from that instant. This makes the error function $f_{\mathrm{A} 1}$ equal to zero and the decision function $\eta_{\mathrm{A} 1}$ grows faster than others. If this decision function exceeds the threshold value, it will generate a fault alarm for actuator struck at minimum position.

When the actuator is struck at 'maximum struck position', the state $\mathrm{x}_{2}$ and state estimate $\hat{\mathrm{x}}_{\mathrm{B} 1}$ are equal since they are applied with same control input from the failure instant. This makes the error function $f_{B 1}$ equal to zero and the decision function $\eta_{\mathrm{B} 1}$ grows faster. It will generate a fault alarm for actuator struck at maximum position while this decision function exceeds the threshold value. The decision function $\eta_{\mathrm{C} 1}$ will grow faster for the actuator struck at last maintained position and generate the respective fault alarm.

Under controller failure, the state estimates $\hat{x}_{\mathrm{A} 1}$ and $\hat{x}_{23}$ are expected to be equal since they are applied with same control input from that instant. This makes the error function $f_{U 1}$ equal to zero and the decision function $\eta_{U 1}$ grows faster than others. Similar set of error functions and actuator fault decision functions are generated from state $\mathrm{x}_{1}$ and state $\mathrm{x}_{2}$ also.

\section{Actuator Fault Confirmation}

The fault identification logic identifies the actuator faults and generates respective fault alarms. As the threshold values are fixed for early detection of fault, dependence on one such decision may generate false alarms in some process perturbation conditions even if it is actually not an actuator fault. A fault confirmation logic is formed with two other multiple model observers to make decisions on actuator faults. Fault will be confirmed only if all multiple model observers make same decision on actuator faults. Error functions and actuator fault decision functions are generated from MMO of state $\mathrm{x}_{1}$ and state $\mathrm{x}_{2}$ also for this purpose.

Since the values of error functions are not generated in same ranges on actuator faults, the product of the error functions may not result in greater values even under respective faults. Hence threshold values are fixed for error functions and the error function values will be 1 if they cross their threshold values. Thus,

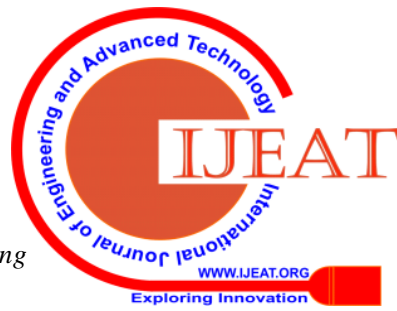




$\left.\begin{array}{l}\text { If } \mathrm{f}_{\mathrm{Ai}}>\Gamma_{\mathrm{Ai}} \text {, then } \mathrm{f}_{\mathrm{Ai}}=1, \\ \text { If } \mathrm{f}_{\mathrm{Bi}}>\Gamma_{\mathrm{Bi}} \text {, then } \mathrm{f}_{\mathrm{Bi}}=1 \\ \text { If } \mathrm{f}_{\mathrm{Ci}}>\Gamma_{\mathrm{Ci}} \text {, then } \mathrm{f}_{\mathrm{Ci}}=1 \\ \text { If } \mathrm{f}_{\mathrm{Ui}}>\Gamma_{\mathrm{Ui}} \text {, then } \mathrm{f}_{\mathrm{Ui}}=1\end{array}\right\}$ for $\mathrm{i}=1,2$ and 3

The decision functions will become 1 for the occurrence of their respective actuator faults. The fault alarm will be generated for actuator faults as given by

$$
\begin{aligned}
& \text { If } \eta_{\mathrm{A} 1}=1 \text { AND } \eta_{\mathrm{A} 2}=1 \text { AND } \eta_{\mathrm{A} 3}=1 \text {, then } \mathrm{F}_{\mathrm{A}}=1 \\
& \text { If } \eta_{\mathrm{B} 1}=1 \text { AND } \eta_{\mathrm{B} 2}=1 \text { AND } \eta_{\mathrm{B} 3}=1 \text {, then } \mathrm{F}_{\mathrm{B}}=1 \\
& \text { If } \eta_{\mathrm{C} 1}=1 \text { AND } \eta_{\mathrm{C} 2}=1 \text { AND } \eta_{\mathrm{C} 3}=1 \text {, then } \mathrm{F}_{\mathrm{C}}=1 \\
& \text { If } \eta_{\mathrm{U} 1}=1 \text { AND } \eta_{\mathrm{U} 2}=1 \text { AND } \eta_{\mathrm{U} 3}=1, \text { then } \mathrm{F}_{\mathrm{U}}=1
\end{aligned}
$$

where $F_{A}, F_{B}$ and $F_{C}$ are the Fault Alarms for actuator struck at minimum position, struck at maximum position and struck at last maintained position respectively and $\mathrm{F}_{\mathrm{U}}$ is the fault alarm for controller failure.

\section{Reconfiguration of Control Law}

On detection and identification of actuator fault, the control law should be reconfigured so that the objective of the control system is achieved. Based on the type of fault, relevant control action will be taken. Since only two control valves are provided for control in three tanks interacting level process, the reconfiguration is same for all type of faults in this work.If any type of actuator failure is reported by the fault detection and identification logic, the input $\mathrm{u}_{1}$ will be stopped and the control valve $\mathrm{CV}_{1}$ is removed from the working scenario through interlocks since both 'struck at maximum flow position' and 'struck at last maintained position' fault will lead to system instability and input $\mathrm{u}_{2}$ will come into action through its own state feed back to maintain the level in tank 3 at the desired level. The actuator fault of struck at minimum flow position will not make much problems and the control input $\mathrm{u}_{2}$ will come in action to maintain the desired level.

The basic control law for $\mathrm{u}_{2}$ is given by

$$
\mathrm{u}_{2}=-\mathrm{K}_{1} \mathrm{x}_{1}-\mathrm{K}_{2} \mathrm{x}_{2}-\mathrm{K}_{3} \mathrm{x}_{3}-\mathrm{K}_{\mathrm{IN}}\left(\mathrm{h}_{3, \mathrm{ref}}-\mathrm{x}_{3}\right)
$$

where the values of state feedback gains $\mathrm{K}_{1}, \mathrm{~K}_{2}, \mathrm{~K}_{3}$ and $\mathrm{K}_{\mathrm{IN}}$ are 3.7707, 3.5659 and 3.1659 respectively for input $\mathrm{u}_{2}$.

Results And Discussion

\section{No actuator Failure}

The actuator fault detection and identification logic is implemented in three tanks interacting level tanks. Fig.12 shows the results under no failure condition. Since the value of the actuator fault decision function $\eta_{\mathrm{A}}$ does not exceed its threshold value, no actuator fault is reported and no fault alarms are generated.

\section{Struck at minimum flow position}

The 'struck at minimum flow position' introduced in the control valve $\mathrm{CV}_{1}$ at $150 \mathrm{~s}$ and the results are observed. Fig. 13 shows the various trends of levels, the estimates of states $\mathrm{x}_{1}$ and $\mathrm{x}_{2}$, the decision function $\eta_{\mathrm{A}}$, the control inputs. The error functions and the fault alarms generated by each model in multiple model observer scheme are also shown in this figure. A fault alarm for 'struck at minimum position' is generated at $163 \mathrm{~s}$. The control action is taken care by the control input $\mathrm{u}_{2}$ and the state feedback control system is able to maintain the level in third tank at the set point $20 \mathrm{~cm}$.
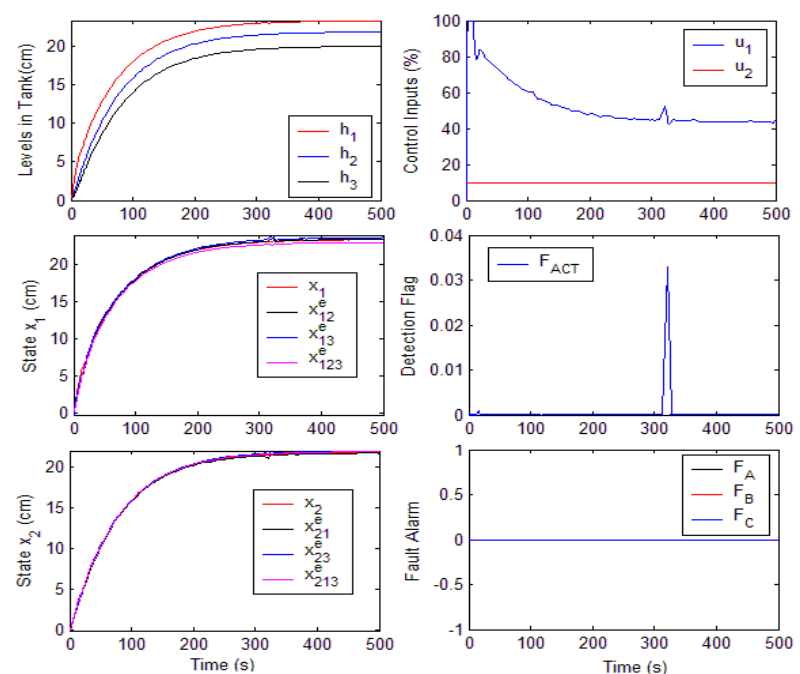

Fig 12Trends on no actuator failure condition
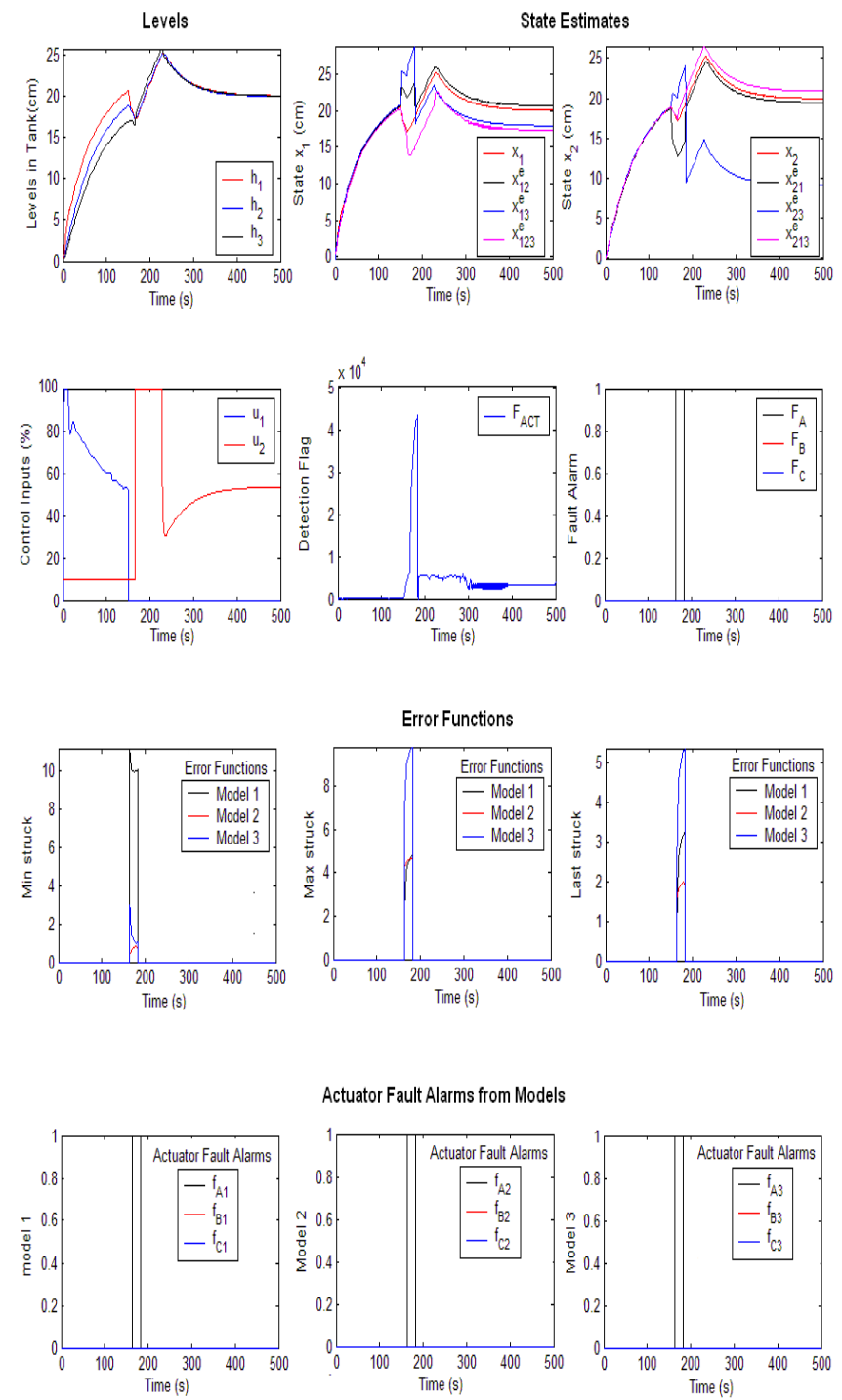

\section{Fig 13 Trends on actuator struck at minimum flow position}

Since the flow to the first tank is not supplied, the level trends of $h_{1}$ and $h_{2}$ are changed and they settle at the same level as that of third tank. 


\section{Struck at maximum flow position}

The actuator is introduced with 'struck at maximum flow position' fault at $150 \mathrm{~s}$ and the performance is studied. The results are shown in Fig.14. The fault is detected and identified at $153 \mathrm{~s}$. The control input $u_{2}$ is applied to the process through state feedback and the level $\mathrm{h}_{3}$ is maintained at the desired level.

Struck at last position

The actuator is made struck at $150 \mathrm{~s}$ at its last position. Actuator fault detection and identification logic detects this fault at $184 \mathrm{~s}$. It takes nearly $34 \mathrm{~s}$ to recognize this fault. The trends are shown in Fig.15.

The control input $\mathrm{u}_{2}$ comes into action from $184 \mathrm{~s}$ and maintains the level at the desired value. The controller failure is physically not introduced. However it is observed that the decision function for this fault grows faster on introducing the failure in control signal.

The proposed fault detection and identification scheme performs well under all actuator faults. Reconfiguration is done and the state feedback with control input $\mathrm{u}_{2}$ is able to control the level at the set point.
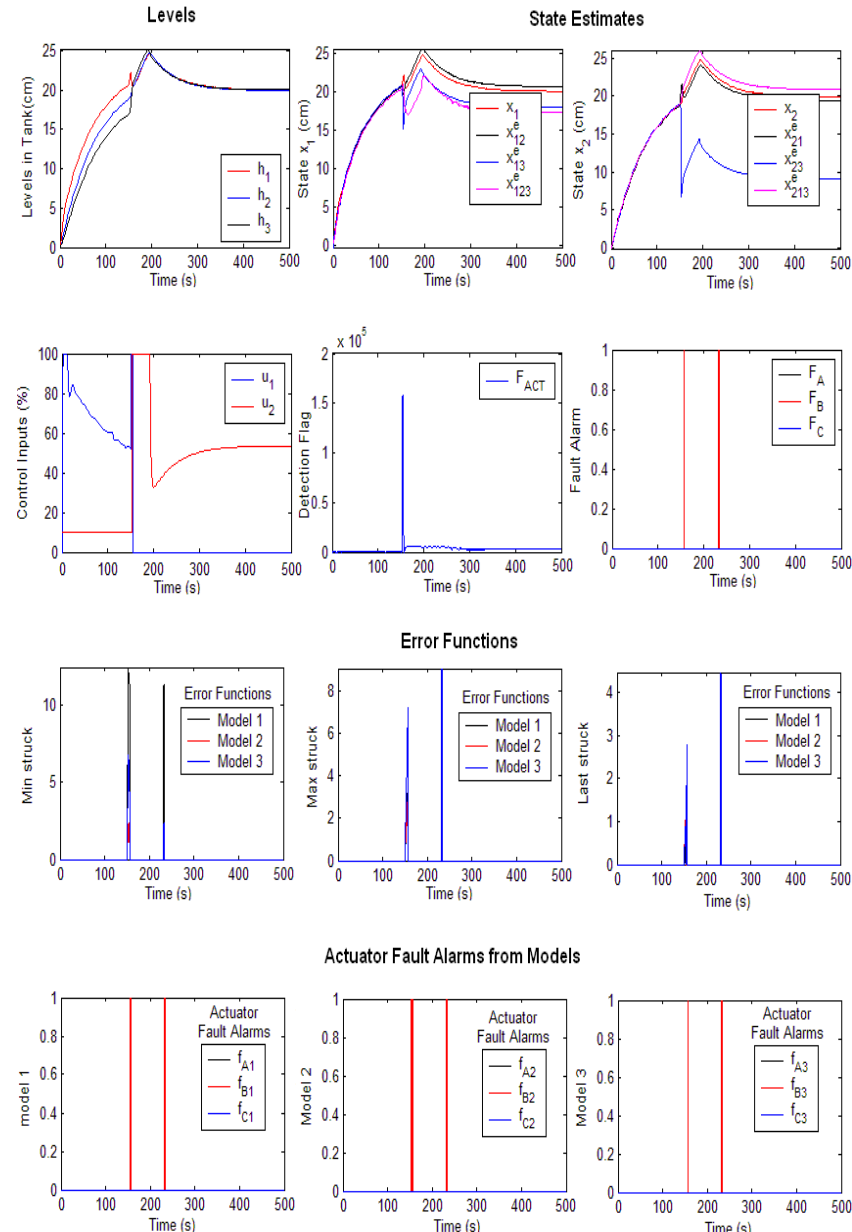

Actuator Fault Alarms from Model
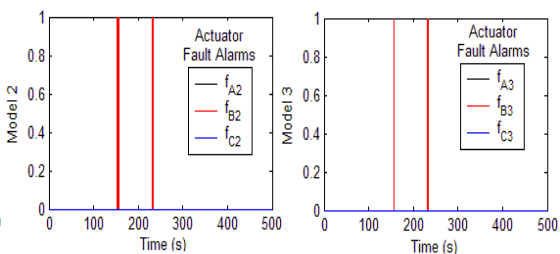

Fig 14 Trends on actuator struck at maximum flow position
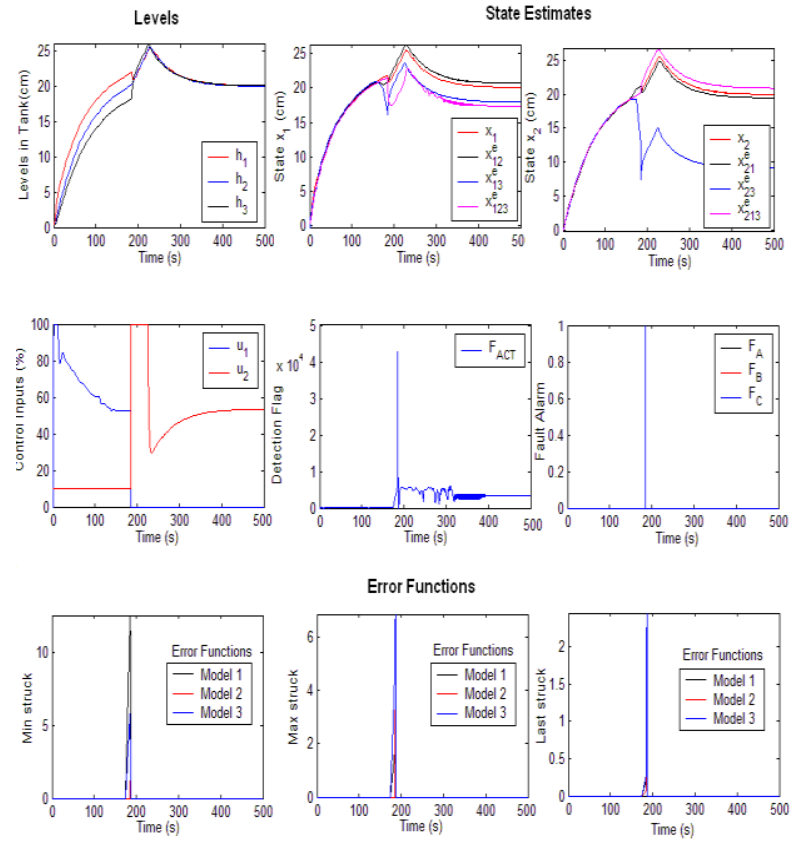

Actuator Fault Alarms from Models
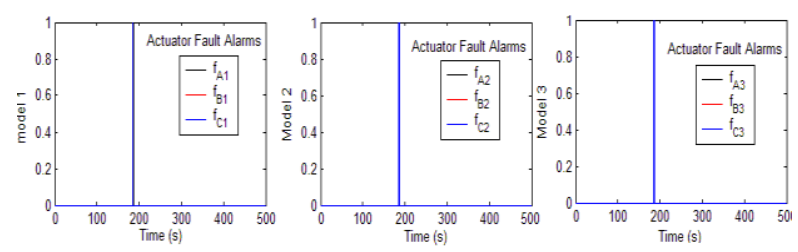

Fig 15 Trends on actuator struck at last maintained position

\section{CONCLUSION}

Three ANFIS dedicated observers are designed to give two estimated values for each level measurement. The decision functions for Fault Detection and Identification logic for Controller and Actuator failures are formed from the decision functions of sensor failures based on Multiple Model Observer and generate the fault alarm when these decision functions exceed their threshold values. Fault identification scheme uses a multiple model observer to develop decision functions. Four models are developed with a dedicated observer to represent the four actuator faults 'struck at minimum flow position', 'struck at maximum flow position', 'struck at last maintained position' and the controller failure respectively. The control inputs to the four models of the observer are fixed at $0 \%, 100 \%$, value at the time of failure and the actual control input $u_{1}$ respectively. Decision functions are developed from the outputs of these models to identify the actuator faults. Fault confirmation logic uses two more multiple model observers to avoid false alarms.

All types of Actuator failures are introduced individually and this method detects and identifies the failures correctly nearly 10 seconds after the instant of failure to generate actuator fault alarms. If any actuator failure is identified in control valve actuated by the control input $\mathrm{u}_{1}$, the control action is shifted to the control valve actuated by the control input $\mathrm{u}_{2}$ to maintain the level at set point. It performs well

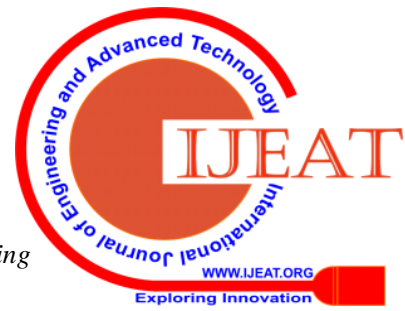


for any set points. No false alarm is reported in any case.

\section{REFERENCES}

1. Huang C.Y. and Stengel R.F., 'Restructurable Control System Using Proportional Integral Implicit Model Following', J. guidance, Dynamics and Control, vol. 13, 1990, pp. 303-339.

2. Joshi S.M., 'Design of Failure accommodating Multiloop LQG-type controllers', IEEE Trans. Automatic Control, vol. 32, 1987, pp. 740-745.

3. Morse W.D. and Ossman K.A., 'Model Following Reconfigurable Flight Control Systems for the AFT1/ F16 ,

4. J. Guidance, Dynamics and Control, Vol. 13, No. 6, 1990, pp. 969-976.

5. Noura H.D., Sauter D. and Aubrun C., 'A Fault Detection and accommodation method applied to an inverted pendulum', Proc. IEEE conf. Control Appl., Glasgow, Scotland, 1994, pp. 1397-1401.

6. Bajpai G., Chang B.C. and Lau A., 'Reconfiguration of Flight Control Systems for Actuator Failures', IEEE AESS Magazine, 2001, pp. 29-33.

7. Gavito V.F. and Collins D.J., 'Application of Eigenstructure Assignment to Self Reconfiguring Aircraft MIMO Controllers', Proc. AIAA Guidance and Control Conf., 1987, pp. 1-12.

8. Jiang J. and Zhao Q. (1998), 'Fault Tolerant Control Synthesis using Imprecise Fault Identification and Reconfigurable Control', Proc. 1998 IEEE ISIC/CIRA/ISAS Joint Conf., Gaithersburg, MD, USA, pp. 169-174.

9. Maybeck P.S. and Stevens R.D., 'Reconfigurable Flight Control via Multiple Model Adaptive Control Methods', Proc. 29th IEEE Conf. Decision and Control, 1990.

10. Yang Z., Izadi-Zamanabadi R. and Blanke M., 'On-line Multiple Model based Adaptive Control Reconfiguration for a Class of Nonlinear Control Systems', Proc. IFAC Symposium on Fault Detection, Supervision and safety for Technical Processes, SAFEPROCESS '2000, 2000.

11. Zhang Y. and Jiang J., 'An Interacting Multiple Model based Fault Detection, Diagnosis and Fault Tolerant Control Approach', Proc. IEEE Conf. Decision and Control CDC '99, Phoenix, Arizona, USA, 1999, pp. 3593-3598.

12. A. Aihua Zhang, B. Chengcong Lv, C. Zhiqiang Zhang, D. Zhiyong She, 'Finite Time Fault Tolerant Attitude Control-Based Observer for a Rigid Satellite Subject to Thruster Faults', Special Section On Advanced Control And Health Management for Aircraft And its Propulsion System, vol. 5, 2017.

13. Xudong Wang, Zhongyang Fei , Huijun Gao , and Jinyong $\mathrm{Yu}$, 'Integral-Based Event-Triggered Fault Detection Filter Design for Unmanned Surface Vehicles', IEEE transactions on industrial informatics, vol. 15, no. 10, october 2019.

14. Xiao He, Zidong Wang, Yang Liu, Liguo Qin,and Donghua Zhou, 'Fault-Tolerant Control for an InternetBased Three-Tank System: Accommodation to Sensor Bias Faults', IEEE Transactions On Industrial Electronics, Vol. 64, No. 3, 2017.

15. Balle, Fischerd P.M., Fussel D. and Isermann R., 'Integrated Control, Diagnosis and Reconfiguration of a Heat Exchanger', Proc. American Control Conf., ACC'97, Albuquerque, USA, 1997, pp. 922-926.

16. Chang G., Zrida J. and Birdwell J.D., 'Knowledge based Distribution System Analysis and Reconfiguration', IEEE Trans. on Power Systems, vol. 5, 1990, pp. 744 749 .

17. Ho H.S. and Balakrishnan S.N., 'Fuzzy Logic in Restructurable Flight Control Systems', Proc. American
Control Conf., Seattle, Washington, vol. 2, 1995, pp. $1362-1366$

18. Kline-Schoder, Rauch R. and Youssef H., 'Fault Detection, Isolation and Reconfiguration for Aircraft using Neural Networks', Proc. AIAA Guidance, Navigation and Control Conf., Monterey, Ca., 1993, pp. 3876-3880

19. Napolitano M.R., Casdorph V., Neppach C. and Naylor S., 'On-line Learning Neural Architectures and CrossCorrelation Analysis for Actuator Failure Detection and Identification', Int. J. Control, vol. 63, No. 3, 1996, pp. 433-455.

20. Q. Wu and M. Saif, "Robust fault diagnosis for a satellite large angle attitude system using an iterative neuron PID (INPID) observer," in Proc. Amer. Control Conf., Minneapolis, MN, USA, 2006, pp. 5710-5715.

21. W.Chen and M.Saif, "Observer-based fault diagnosis of satellite systems subject to time-varying thruster faults," Trans. ASME, J. Dyn. Syst. Meas. Control, vol. 129, no. 3, 2007, pp. 352-356.

22. S.Nagarajan, J.Shanmugam and T.R.Rangaswamy, 'MANFIS Observer based Sensor Fault Detection and Identification in Interacting Level Process with NN based Threshold Generator', International Journal of Softcomputing, vol.3(5), 2008, pp.344 - 354 .

23. Stefani, Shahian, Savant, and Hosteller, Design of feedback control systems. 4th ed., Oxford University Press, 2002.

24. S.Nagarajan and B.Karthikeyan, 'Control of Interacting Level Process Under Sensor Failure Conditions using Coactive Adaptive Neuro-Fuzzy Observer', International Journal of New Technologies in Science and Engineering, vol. 2, Issue. 4, 2015.

25. J. S. Jang, C. T. Sun, and E. Mizutani, Neuro-Fuzzy and Soft Computing - A Computational approach to Learning and Machine Intelligence, Prentice Hall, Upper saddle River,NJ, 1997

\section{AUTHORS PROFILE}

S.Nagarajan is working as Professor and Head in the

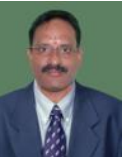
Dept. Electronics and Instrumentation Engineering in Easwari Engineering College, Chennai. He completed his PG in Control Systems from PSG College of Technology, Coimbatore in 1996 and Ph.D from Anna University in 2008. His research areas are Intellegent control and Fault Tolerant Control.

K..Kalaivani is working as Associate Professor in the Dept. of Electronics and Instrumentation Engineering in Easwari Engineering College, Chennai. Her research areas are Process control, Embedded Systems and Image Processing

P.Navaseelan is working as Associate Professor in the Dept. of Electronics and Instrumentation Engineering in Easwari Engineering College, Chennai. His research areas are Process Control and Fault Diagnosis.

T.Kalaiselvi is working as Assistant Professor in the Dept. of Electronics and Instrumentation Engineering in Easwari Engineering College, Chennai. Her research areas are Process Control and Medical Electronics

S.Sobana is working as Associate Professor in the Dept. of Electronics and Instrumentation Engineering in Easwar Engineering College, Chennai. Her research area is Process Control. 